\title{
Two chitin metabolic enzyme genes from Hyriopsis cumingii: cloning, characterization, and potential functions
}

\author{
G.-L. Wang ${ }^{1 *}$, B. Xu ${ }^{1 *}$, Z.-Y. Bai ${ }^{1}$ and J.-L. Li ${ }^{1,2}$ \\ ${ }^{1}$ Key Laboratory of Freshwater Germplasm Resources, \\ Ministry of Agriculture, Shanghai, China \\ ${ }^{2}$ Aquaculture Division, E-Institute of Shanghai Universities, \\ Shanghai Ocean University, Shanghai, China \\ *These authors contributed equally to this study. \\ Corresponding author: J.-L. Li \\ E-mail: j1li@shou.edu.cn \\ Genet. Mol. Res. 11 (4): 4539-4551 (2012) \\ Received January 23, 2012 \\ Accepted June 22, 2012 \\ Published October 15, 2012 \\ DOI http://dx.doi.org/10.4238/2012.October.15.4
}

\begin{abstract}
Chitin, the second most important natural polymer in the world, and its N-deacetylated derivative chitosan are found in a wide variety of organisms. These versatile biopolymers are associated with a broad range of biological functions. This article is the first to report the potential functions of 2 chitin metabolic enzyme genes from Hyriopsis cumingii. A chitinase-3 gene (Chi-3) and a chitin deacetylase gene (Cda) were cloned from H. cumingii and characterized. Semi-quantitative reverse transcription polymerase chain reaction analysis revealed that the $C d a$ gene was expressed in blood, mantle, liver, stomach, kidney, intestine, gill, and foot, whereas Chi-3 was also expressed in those tissues but not in blood. The tissue-specific expression of $\mathrm{H}$. cumingii Chi-3 indicated that other Chi genes may be involved in the $H$. cumingii immune system. Real-time quantitative polymerase chain reaction analysis showed that the expression of Chi-3 was significantly $(\mathrm{P}<$ 0.05 ) upregulated $12 \mathrm{~h}$ after shell damage, suggesting that Chi-3 might hydrolyze superfluous chitin after shell recovery and play a role in shell formation. Conversely, $C d a$ expression did not change significantly ( $\mathrm{P}$
\end{abstract}


$>0.05)$ to maintain a certain degree of acetylation in chitin/chitosan. This study enriches the basic research on chitin metabolic genes and lays foundations for further research of shell regeneration in mussels.

Key words: Hyriopsis cumingii; Chitinase-3 gene; Potential functions; Chitin deacetylase gene; Expression

\section{INTRODUCTION}

The fundamental physiological role of chitinase is the degradation of chitin into Nacetyl-D-glucosamine dimers and trimers, whereas chitin deacetylase completes the catalysis of chitin into chitosan, which is the deacetylation polymer of N-acetyl-D-glucosamine (degree of N-deacetylation $>50 \%$ ) (Kumirska et al., 2010). Thus, chitosan is the collective name for a group of fully and partially deacetylated chitins, but a rigid nomenclature defining the degree of N-deacetylation between chitin and chitosan has yet to be defined (Ravi Kumar, 2000). Chitin/chitosan have been identified as versatile biopolymers for a broad range of biological functions, including shell regeneration in mollusks, crustaceans, and insects (Suzuki et al., 2009; Proespraiwong et al., 2010; Zhang et al., 2011); repair of wounded skin, nerve, cartilage, and bone (Riccardo, 2009), and immunity (Badariotti et al., 2007, 2011). In recent years, studies investigating the functions of chitin/chitosan in bivalves have concentrated mainly on Crassostrea gigas (Badariotti et al., 2007, 2011), Mytilus galloprovincialis (Weiss et al., 2009), and Pinctada fucata (Suzuki et al., 2009). Badariotti et al. (2011) have found that chitinase plays significant roles in various biological processes such as development, tissue remodeling, and immunity in C. gigas by regulating chitin. Weiss et al. (2009) have demonstrated the presence of covalently attached, hydrophobic amino acid side chains in the chitin matrix in the bivalve mollusk M. galloprovincialis using a combination of infrared spectroscopy and mass spectrometry. This finding suggests an active role of such chemically modified chito-oligosaccharides in the creation of a defined interface and guidance of periodic matrix textures, which results in the unique material properties of mollusk shells. Suzuki et al. (2009) have proposed a model for the molecular mechanism of nacreous layer formation in P. fucata and have suggested that chitin plays an important role in protein collection during that process.

The triangle sail mussel (Hyriopsis cumingii), an endemic species in China, is found mainly in large lakes and rivers (Liu, 1979). Since artificial propagation of H. cumingii was first achieved in 1979, the species has become the most important mussel for commercial freshwater pearl production. Currently, annual production of freshwater pearls has reached 1800 metric tons in China, which accounts for more than $95 \%$ of the total world output (Li et al., 2005). More than $90 \%$ of Chinese freshwater pearls are produced by the triangle sail mussel (Wang et al., 2006). Despite the commercial importance of this mussel, little is known about the molecular mechanisms involved in the chitin/chitosan functions that underlie shell formation and other biological processes.

To understand these mechanisms better, we constructed a complementary DNA (cDNA) library using messenger RNA from the $H$. cumingii mantle. In total, 29 expressed sequence tags (ESTs) were identified that showed similarity to genes potentially involved in shell formation (Bai et al., 2010). In the present study, 2 chitin metabolic enzyme genes were cloned from $H$. cumingii using 2 defined ESTs: chitinase-3 (Chi-3) and chitin deacetylase $(\mathrm{Cda})$. These enzymes were characterized, and the potential physiological functions of the genes were investigated by examining tissue-specific expression and their expression in response to shell damage. 


\section{MATERIAL AND METHODS}

\section{Animals and RNA extraction}

Adult specimens of $H$. cumingii (mean mass, $100 \mathrm{~g}$ ) were cultured individually by the Weiwang Company (Jinhua, Zhejiang Province, China). Animals were raised at $28^{\circ} \mathrm{C}$ in 400-L aerated aquaria for 2 weeks before the experiment and fed green algae. Three healthy mussels were used as assay materials for the semi-quantitative reverse transcription polymerase chain reaction (RT-PCR) experiments. Blood, mantle, liver, stomach, kidney, intestine, gill, and foot tissues were collected from each mussel, and total RNA was isolated from each of the tissues. For the quantitative real-time PCR (qRT-PCR) experiments, 24 healthy mussels were used, of which 20 individuals had their shell damaged according to Mount et al. (2004) method, with some modifications. A V-shaped notch was cut in the shell margin close to the adductor muscle of the mussels. The mussels were then divided into 5 groups at random, each of which contained 4 individuals. The groups were sampled at 3, 6, 9, 12, and 24 $\mathrm{h}$ and then killed. About $1 \mathrm{~cm}^{2}$ of the mantle tissue around the cut was separated. Meanwhile, the mantles of 4 individuals without shell notching were separated similarly as controls. All tissues were frozen in liquid nitrogen before being stored at $-80^{\circ} \mathrm{C}$. Total RNA was isolated using the RNAiso Plus (TaKaRa, Japan) and stored at $-80^{\circ} \mathrm{C}$ after incubation with RNase-free gDNA Eraser (TaKaRa).

\section{Cloning the full-length cDNA of $C h i-3$ and $C d a$}

A 627-bp fragment of Chi-3 and a 766-bp fragment of $C d a$ were obtained from a normalized cDNA library of mantle tissue from $H$. cumingii (Bai et al., 2010). These were used to clone the full-length cDNA of Chi-3 and $C d a$ with the rapid amplification of cDNA ends (RACE) method using the SMART ${ }^{\mathrm{TM}}$ RACE cDNA Amplification Kit (5'-RACE; Clontech, USA) and 3'-Full RACE Core Set Ver. 2.0 (3'-RACE; TaKaRa) according to manufacturer protocols. RACE PCR was performed using primer sets designed in the adapter sequences of the kit and gene-specific primers designed in the cloned PCR fragments (Table 1).

5 '-RACE reactions were carried out in a $50-\mu \mathrm{L}$ reaction volume containing $34.5 \mu \mathrm{L}$ PCR-grade water, $5 \mu \mathrm{L}$ 10X Advantage 2 PCR buffer, $1 \mu \mathrm{L}$ 50X deoxyribonucleotide triphosphate mix $(10 \mathrm{mM}), 1 \mu \mathrm{L} 50 \mathrm{X}$ Advantage 2 Polymerase mix, $2.5 \mu \mathrm{L}$ 5'-RACE-ready cDNA supplied with the 5'-RACE kit, $5 \mu \mathrm{L}$ 10X Universal Primer A Mix $(10 \mu \mathrm{M})$, and $1 \mu \mathrm{L} 10 \mu \mathrm{M}$ gene-specific primer under the following conditions: 5 cycles of $94^{\circ} \mathrm{C}$ for $30 \mathrm{~s}$ and $72^{\circ} \mathrm{C}$ for 3 min; 5 cycles of $94^{\circ} \mathrm{C}$ for $30 \mathrm{~s}, 70^{\circ} \mathrm{C}$ for $30 \mathrm{~s}$, and $72^{\circ} \mathrm{C}$ for $3 \mathrm{~min}$, and 25 cycles of $94^{\circ} \mathrm{C}$ for $30 \mathrm{~s}, 68^{\circ} \mathrm{C}$ for $30 \mathrm{~s}$, and $72^{\circ} \mathrm{C}$ for $3 \mathrm{~min}$.

3'-RACE reactions were carried out in a $50-\mu \mathrm{L}$ reaction volume containing $2.5 \mu \mathrm{L}$ 3'-RACE-ready cDNA supplied with the 3'-RACE kit, $7.5 \mu \mathrm{L} 1 \mathrm{X}$ cDNA dilution buffer II, 2 $\mu \mathrm{L} 10 \mu \mathrm{M}$ gene-specific primer, $2 \mu \mathrm{L} 10 \mu \mathrm{M}$ 3'-RACE Outer Primer, $4 \mu \mathrm{L} 10 \mathrm{X}$ LA PCR buffer II ( $\mathrm{Mg}^{2+}$-free), $3 \mu \mathrm{L} 25 \mu \mathrm{M} \mathrm{MgCl}_{2}, 0.25 \mu \mathrm{L} 5 \mathrm{U} / \mu \mathrm{L}$ TaKaRa LA Taq, and $28.75 \mu \mathrm{L}$ distilled $\mathrm{H}_{2} \mathrm{O}$ under the following conditions: $94^{\circ} \mathrm{C}$ for $3 \mathrm{~min}, 30$ cycles of $94^{\circ} \mathrm{C}$ for $30 \mathrm{~s}, 55^{\circ} \mathrm{C}$ for $30 \mathrm{~s}$, and $72^{\circ} \mathrm{C}$ for $3 \mathrm{~min}$. The PCR product was subcloned into a pGEM-T Easy Vector (Promega, USA). Positive clones were sequenced on an ABI PRISM 3730 Automated Sequencer using BigDye Terminator v3.1 (Applied Biosystems, USA). 


\section{Sequence analysis}

The open reading frames (ORFs) of Chi-3 and Cda cDNA were identified using ORF Finder (http://www.ncbi.nlm.nih.gov/projects/gorf/). Nucleotide and amino acid sequence identity and the prediction of conserved domains in the peptide were performed using the Basic Local Alignment Search Tool program (GenBank, National Center for Biotechnology Information). The putative amino acid sequence was analyzed for the presence of signal peptides using the SignalP 3.0 Server (http://www.cbs.dtu.dk/services/SignalP/) (Bendtsen et al., 2004). Multiple sequence alignments were performed using ClustalW 1.8 (Jeanmougin et al., 1998). The Needle program (http://www.ebi.ac.uk/Tools/emboss/align/) was used to calculate the identities among Chi-3 and Cda genes from different species. A phylogenetic tree was constructed based on the deduced full-length amino acid sequence alignments using the neighbor-joining algorithm and the maximum likelihood method in the Molecular Evolutionary Genetics Analysis 5.0 program. The reliability of the estimated tree was evaluated using the bootstrap method with 1000 pseudo-replications. The accession numbers of the sequences used in this analysis are listed in Figures 1-4.

\section{Semi-quantitative RT-PCR analysis}

Tissue expression of Chi-3 and $C d a$ was investigated using semi-quantitative RT-PCR. Total RNA was isolated as above from blood and mantle, liver, stomach, kidney, intestine, gill, and foot tissues of adult individuals of $H$. cumingii. Equal quantities $(0.4 \mu \mathrm{g})$ of total RNA from the various tissues and blood were reverse transcribed into cDNA using PrimeScript RTPCR Kit primers in $20 \mu \mathrm{L}$ reaction mixtures (TaKaRa). The generated cDNA was used as the template for PCR, which was catalyzed with Taq DNA polymerase (TaKaRa) and typically consisted of 30 cycles of $94^{\circ} \mathrm{C}$ for $30 \mathrm{~s}, 55^{\circ} \mathrm{C}$ for $30 \mathrm{~s}, 72^{\circ} \mathrm{C}$ for $30 \mathrm{~s}$, and then a hold at $4^{\circ} \mathrm{C}$. The 30-cycle reaction proved to be optimal among the 18-, 22-, 26-, 30-, and 34-amplification cycles for all of the cDNAs used. The primer pairs used for the amplifications are given in Table 1. $\beta$-actin was used as the internal control with gene-specific primers designed according to a mussel $\beta$-actin cDNA sequence (accession No. HM045420). The PCR products were sub-cloned into a pGEM-T Easy Vector and verified through sequencing. Equal volumes of the PCR products were fractionated on a $1.5 \%$ agarose gel and stained with ethidium bromide. The experiments were repeated using 3 individuals, and the results were consistent.

\begin{tabular}{ll} 
Table 1. Primer sequences used in this study. \\
\hline Primer name & Primer sequence (5'-3') \\
\hline Chi-GSP5 & CCGACCCACTGATCACCTTTTACCA \\
Chi-GSP3 & CAAGTTGAATATCGGACTGGGC \\
Chi-RT-F & CAGTGGGTCGGTTATGATGA \\
Chi-RT-R & GTGCAATGGTGCTCTTGT \\
Chi-qRT-F & AATAGCCCGCTGTTTCCTCAT \\
Chi-qRT-R & CCATACAAGCCCAGTCCGATA \\
Cda-GSP5 & CCTTGATCCGTCAAAAAGCTCTCG \\
Cda-GSP3 & CCAAACGGTTGTCCATCTCCA \\
Cda-RT-F & TCAACCCAGCACGCTTAAAGA \\
Cda-RT-R & TTGTAATCCATGAGGGACACCA \\
Cda-qRT-F & TGACCGTCTGAAGGCAATGGA \\
Cda-qRT-R & GCTTGATAAGGGCGTGGGAT \\
$\beta$-actin-F & ACGGATAACACAAGGAAAGGAAC \\
$\beta$-actin-R & ATGGATGGAAACACGGCTCT \\
\hline
\end{tabular}




\section{qRT-PCR analysis}

Induced expression of Chi-3 and $C d a$ in response to shell damage was investigated using qRT-PCR, which was performed on a CFX96 Real-Time PCR System (Bio-Rad, USA). Total RNA was isolated as described above from the mantles of adult $H$. cumingii individuals after shell damage. Approximately $1 \mu \mathrm{g}$ RNA from each sample was reverse transcribed using the PrimeScript RT Reagent Kit with gDNA Eraser (TaKaRa). The first-strand cDNA was subsequently used as the template for PCR with the primer pairs listed in Table 1. $\beta$-actin was also amplified, and this gene served as the internal control for cDNA normalization (accession No. HM045420). The qRT-PCR mixture consisted of 50 ng cDNA sample, $8.2 \mu \mathrm{L}$ nuclease-free water, $10 \mu \mathrm{L} 2 \mathrm{X}$ SYBR Premix Ex Taq ${ }^{\mathrm{TM}}(\mathrm{TaKaRa})$, and $0.4 \mu \mathrm{L} 10$ $\mu \mathrm{M}$ of each gene-specific primer. The PCR cycling conditions were $95^{\circ} \mathrm{C}$ for $30 \mathrm{~s}$; then 40 cycles of $95^{\circ} \mathrm{C}$ for $5 \mathrm{~s}$ and $60^{\circ} \mathrm{C}$ for $34 \mathrm{~s}$ followed by dissociation curve analysis at $95^{\circ} \mathrm{C}$ for $15 \mathrm{~s}, 60^{\circ} \mathrm{C}$ for $60 \mathrm{~s}$, and $95^{\circ} \mathrm{C}$ for $15 \mathrm{~s}$ to verify the amplification of a single product. The cycle threshold value was determined with the 7500 software v2.0, and data were exported into a Microsoft Excel spreadsheet for subsequent analysis, in which the relative expression ratios of target genes in the treatment groups were calculated using a $2^{-\Delta \Delta C t}$ method (Livak and Schmittgen, 2001) and compared with expression in the controls. The experiment was performed in triplicate.

\section{Statistical analysis}

Data from the qRT-PCR experiment are reported as means \pm standard error, and significant differences between groups were examined with one-way analysis of variance with the Dunnett T3 post hoc test using the SPSS v17.0 software (SPSS, USA). Significance was accepted at $\mathrm{P}<0.05$.

\section{RESULTS AND DISCUSSION}

\section{Cloning and identification of $H$. cumingii $C h i-3$ and $C d a$ cDNAs}

A full-length cDNA encoding Chi-3 (GenBank accession No. JN582038) from $H$. cumingii was obtained from a normalized full-length cDNA library and the 5'- and 3'-RACE experiments. The Chi-3 cDNA was $2523 \mathrm{bp}$, and it consisted of a 196-bp 5'-untranslated region (UTR), a 1962-bp ORF encoding 653 amino acid residues, and a 365-bp 3'-UTR. Basic Local Alignment Search Tool analysis revealed that the deduced amino acid sequence of $\mathrm{H}$. cumingii Chi-3 ( $\mathrm{HcChi}-3$ ) shared $21.3-34.4 \%$ identity with known genes from other organisms and relatively higher identity $27.2-34.7 \%$ with 5 other Chi-3 (see Figure 1). Although this sequence homology is relatively low, the important aspects for the identification of a potential gene are functional domains, evolutionary relationships, and biological functions (Zhou et al., 2011). The catalytic and chitin-binding domains are key structural components of chitinases. Multiple alignments of deduced amino acid sequences of Chi-3 are shown in Figure 1. Similar to other known chitinases, the $\mathrm{HcChi}$-3 peptide was predicted to consist of a signal peptide and 3 conserved domains: a catalytic domain (glycoside hydrolase family 18 domain) followed by 2 chitin-binding 
domains [carbohydrate-binding module family 14 (CBM14) domain]. For most chitinase genes in invertebrates, the CBM14 domain is located near the C-terminus and after the catalytic domain (Huang et al., 2010; Proespraiwong et al., 2010). Only a small number of species display a CBM14 domain interspersed among catalytic domains (Zhu et al., 2008). The phylogenetic tree (see Figure 2) shows $\mathrm{HcChi-3}$ clustered with Chi-3 from C. gigas, suggesting that $\mathrm{HcChi-3}$ belongs to the bivalvia Chi-3 group.

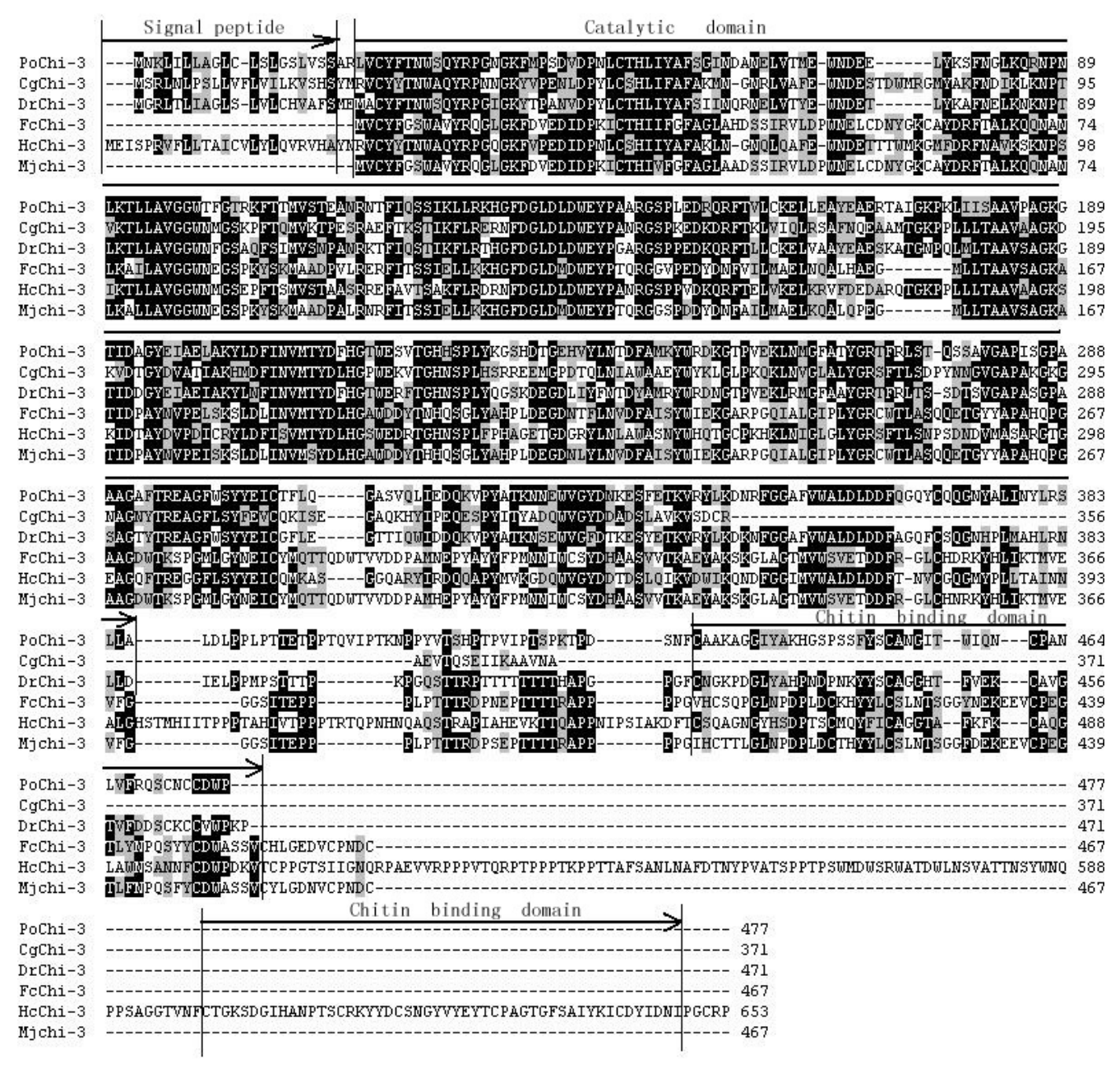

Figure 1. Multiple alignment of deduced amino acid sequences of various $C h i-3$ genes. Above the sequences, the signal peptide, catalytic domain (GH18 domain), and chitin-binding domain (CBM14 domain) are marked out, respectively. Fully conserved amino acid sequences are shaded in black. The protein sequences used for alignment analysis were as follows: Paralichthys olivaceus (Chi-3: BAD15061.1), Crassostrea gigas (Chi-3: CAI96027.1), Danio rerio (Chi-3: NP_998378.1), Fenneropenaeus chinensis (Chi-3: AAY44300.1), Hyriopsis cumingii (Chi-3: JN582038), Marsupenaeus japonicus (Chi-3: BAA22854.1). 


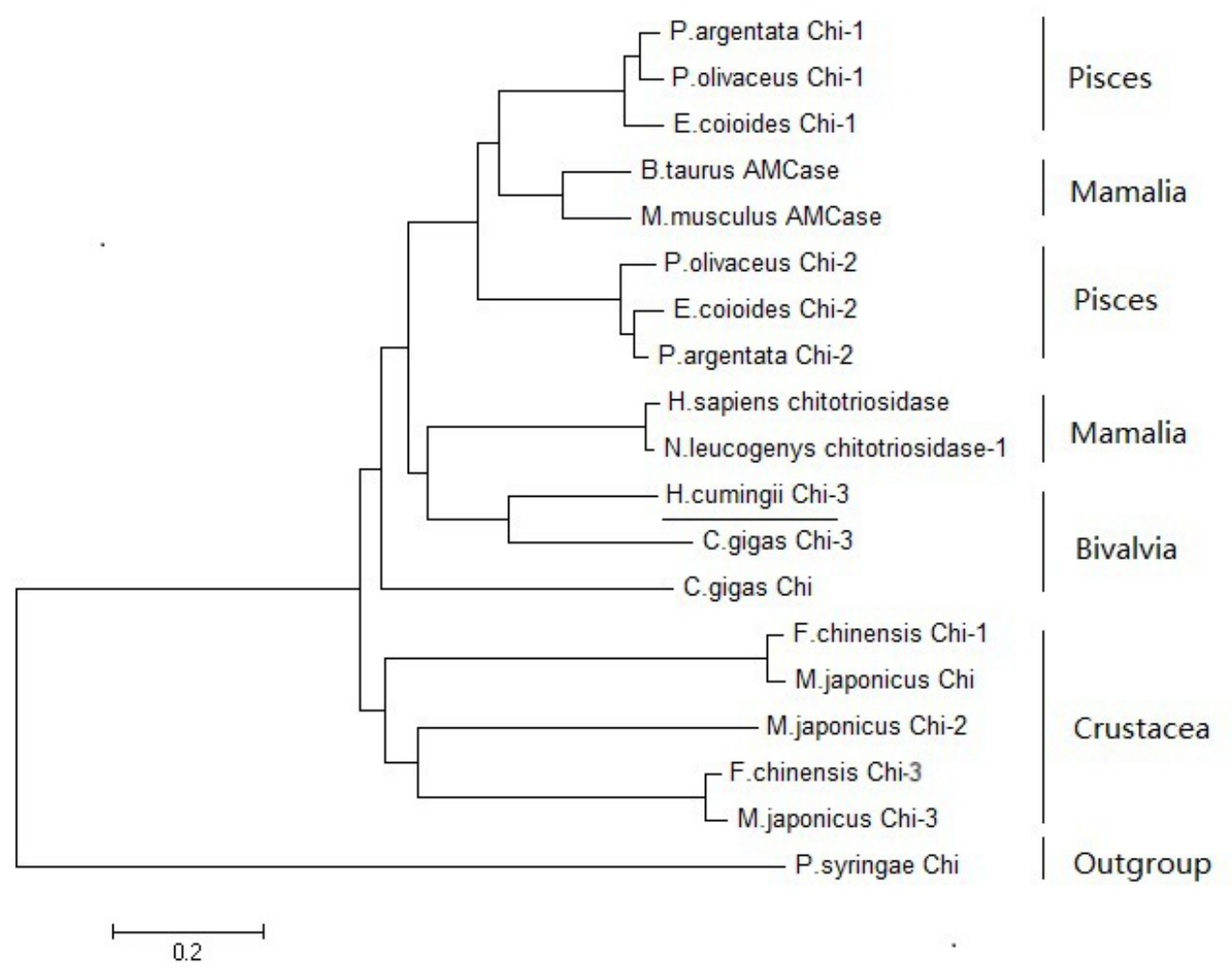

Figure 2. Phylogenetic tree of chitinase (Chi) sequences in animals and chitinase from Pseudomonas syringae as an outgroup, amino acid sequences of full-length Chi were analyzed using the neighbor-joining method in the Mega 5.0 program. The protein sequences used for phylogenetic analysis were as follows: Pennahia argentata (Chi1: BAJ51753.1; Chi-2: BAJ51754.1), Paralichthys olivaceus (Chi-1: BAD15059.1; Chi-2: BAD15060.1; Chi3: BAD15061.1), Epinephelus coioides (Chi-1: ACN38311.1; Chi-2: ACN38310.1), Bos taurus (AAI02932.1), Mus musculus (ABK78778.1), Homo sapiens (EAW91471.1), Nomascus leucogenys (XP_003264627.1), Crassostrea gigas (Chi: CAI96026.1; Chi-3: CAI96027.1), Fenneropenaeus chinensis (Chi-1: ABB85237.1; Chi3: AAY44300.1), Marsupenaeus japonicus (Chi: BAA12287.1; Chi-2: BAA14014.1; Chi-3: BAA22854.1), and Pseudomonas syringae (AAO53944.1).

Regarding the $C d a$ gene, the full-length cDNA from H. cumingii (GenBank accession No. JN582040) was obtained from ESTs in a normalized full-length cDNA library by performing 5'- and 3'-RACE experiments. The $C d a$ cDNA was 2654 bp and contained a 347bp 5'-UTR, a 1938-bp ORF that encodes 645-amino acid residues, and a 369-bp 3'-UTR, as well as a signal peptide, 3 predicted N-glycosylation sites (NTS, NIT, and NET) and a catalytic domain (Polysacc_deac_1; see Figure 3). Cdas in invertebrates are reportedly divided into various groups based on domain patterns (Dixit et al., 2008). In our study, the phylogenetic tree of $C d a$ in invertebrates was constructed based on the $C d a$ domain patterns. As shown in Figure 4, H. cumingii $\mathrm{Cda}(\mathrm{HcCda})$ clustered in group 4, which contains peptides that consist only of a signal peptide and a Polysacc_deac_1 domain. 
CCGGGCTGCAGGGGAAGAAAGGAGAAATACATGAATTTCTTGCTTTGTCCCTGGTTTTGGATATTTGATGAGACTGG 77

AATTAGCATTGTGCTTAGTCGTGTTTCGTTTTCGCCGGATTCTTGTGTGAAAATTAAGGGTATATATTAAAAGGTTACATCCTATCGAGA 167 CCGTTGGATTGATGACTGAAACTGACCCATGCTCTTCTAACTTTCATCGAGAAGAAAAGGAGGAAAATTTGAGCTGTAAGTAGGAACTGA 257 ATTTTACCAGATATCAATCATAGATACCTAAGAGCGTCTGCTGACTATGATTGCTTTGTTCTTTTATTTATAAATTCGGTTTTCGTCAAT 347 ATGTTGAAGCCATTGGTTATAGTTATTGCTATAACAATATTTTTAATCCAGCATGTAACCAGTTCTCCTAAGCAATGTACAGAATGTTTG 437 $\begin{array}{lllllllllllllllllllllllllllllll}M & L & K & P & L & V & I & V & I & A & I & T & I & F & L & I & Q & H & V & T & S & S & P & K & Q & C & T & E & C & L\end{array}$ AAAGATCATACATGCAACCCACCGGACTGTTTTTGCTGCCGAGACAAATTTGTATTTCCCTTTAAATCCTCGGAGATTCCGCAAATGGTC 527 $\begin{array}{lllllllllllllllllllllllllllllll}K & D & H & T & C & N & P & P & D & C & F & C & C & R & D & K & F & V & F & P & F & K & S & S & E & I & P & Q & M & V\end{array}$ TACTTCACATTTGATGACGCCGTCACCGAGCAAGTGTCAGTATTTTACCGAGAGCTTTTTGACGGATCAAGGAAAAACCCAAACGGTTGT 617 $\begin{array}{llllllllllllllllllllllllllllll}Y & F & T & F & D & D & A & V & T & E & Q & V & S & V & F & Y & R & E & L & F & D & G & S & R & K & N & P & N & G & C\end{array}$ CCTATCTCCATGACTCTGTTTATATCTCACGATAACACGAAATACCCCATTGTTAATGAGTTTTATAGAAAAGGAATGGAAATTGCATCT 707 $\begin{array}{llllllllllllllllllllllllllllllllllll}P & I & S & M & T & L & F & I & S & H & D & N & T & K & Y & P & I & V & N & E & F & Y & R & K & G & M & E & I & A & S\end{array}$ CACAGTGTGACTCATAGCCAACTAAATACCTCTAATTTCTTAATGGAGGCCAAATCACAGAGAGAGAACCTAGCTAAACTTGCTGGAATT 797

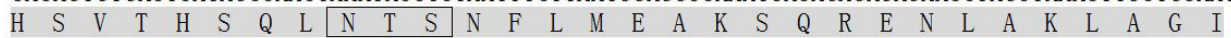
CCAGTCGAATCAATTAAAGGGTGGAGAAGCCCATATCTTAAACCTACTGGTGACCTTCAACCCAGCACGCTTAAAGAACTTGGCTATCTG 887 $\begin{array}{llllllllllllllllllllllllllllll}P & V & E & S & I & K & G & W & R & S & P & Y & L & K & P & T & G & D & L & Q & P & S & T & L & K & E & L & G & Y & L\end{array}$ TACGACGCTACCCTAACATTCAGTAAGAGAAATCTACGCGAGAAAGCACCAACACCTTTCACGTTGGATTATGGTTGGCCGTATGACTGT 977 $\begin{array}{lllllllllllllllllllllllllllllll}Y & D & A & T & L & T & F & S & K & R & N & L & R & E & K & A & P & T & P & F & T & L & D & Y & G & W & P & Y & D & C\end{array}$ AAGGTCAATCCTTGTCCTGCCGGGGTCCATAATGGATTTTGGGAGGTACCAGTGGTGTCCCTCATGGATTACAAACAACAGTATGACTGT 1067

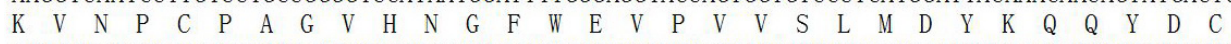
GTATATGTGGATGGATGCATGAATCCACCTCCAGACGAGACAGCGGCTTACCAATTTTTATGGGAGAATTTCAACAGTTACTATACGAAC 1157 $\begin{array}{lllllllllllllllllllllllllllllll}V & Y & V & D & G & C & M & N & P & P & P & D & E & T & A & A & Y & Q & F & L & W & E & N & F & N & S & Y & Y & T & N\end{array}$ TCTCGAATACCCTTTGGCATAAATATGCATCCCTCTTGGTTTTACTATCCTGACCGTCTGAAGGCAATGGACCGATTTATACAGAAACTA 1247 $\begin{array}{lllllllllllllllllllllllllllllll}S & R & I & P & F & G & I & N & M & H & P & S & W & F & Y & Y & P & D & R & L & K & A & M & D & R & F & I & Q & K & L\end{array}$ ACAAGCTTGAATGACGTCTATATCGTAAATGTAGGTCAGGTCATTGAGTGGTTGATGAATCCCACGCCCTTATCAAAGCTGTCAACTTTT 1337

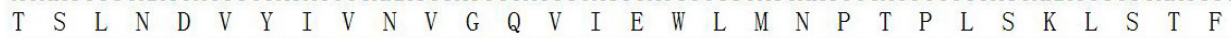
GCACCTTGGAACACTTGTAGATCAAACATAACCTTTTCATTACAAGTACAGGAACCAAGCATGGCTTCATCAATGACGACACAGCAACTA 1427

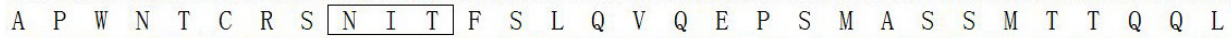
CCGTCTCGTGCTCTTTCCTCGGCTGAGATTCGCAGACAGCATATACTTCATCGCATGCAGAGAATCAGGGAGGAGCTACGGCACAGAAGG 1517 $\begin{array}{lllllllllllllllllllllllllllllll}\mathrm{P} & \mathrm{S} & \mathrm{R} & \mathrm{A} & \mathrm{L} & \mathrm{S} & \mathrm{S} & \mathrm{A} & \mathrm{E} & \mathrm{I} & \mathrm{R} & \mathrm{R} & \mathrm{Q} & \mathrm{H} & \mathrm{I} & \mathrm{L} & \mathrm{H} & \mathrm{R} & \mathrm{M} & \mathrm{Q} & \mathrm{R} & \mathrm{I} & \mathrm{R} & \mathrm{E} & \mathrm{E} & \mathrm{L} & \mathrm{R} & \mathrm{H} & \mathrm{R} & \mathrm{R}\end{array}$ CTGAATATTGATGCAGAAAATACACAACCCTTAATTATAAATCAGCAGCAACAACAACAACAGCTTATAGAGCAAAAAAGATTACAGCAA 1607 $\begin{array}{lllllllllllllllllllllllllllllll}\mathrm{L} & \mathrm{N} & \mathrm{I} & \mathrm{D} & \mathrm{A} & \mathrm{E} & \mathrm{N} & \mathrm{T} & \mathrm{Q} & \mathrm{P} & \mathrm{L} & \mathrm{I} & \mathrm{I} & \mathrm{N} & \mathrm{Q} & \mathrm{Q} & \mathrm{Q} & \mathrm{Q} & \mathrm{Q} & \mathrm{Q} & \mathrm{Q} & \mathrm{L} & \mathrm{I} & \mathrm{E} & \mathrm{Q} & \mathrm{K} & \mathrm{R} & \mathrm{L} & \mathrm{Q} & \mathrm{Q}\end{array}$ GCAAGACAACAGCAAAACATAATTGTGTCATCAAGCATTTTGGATAGGTCTGATGTACGAGTACCTCAAGTTACCCGTCGGCATCAAGAA 1697 $\begin{array}{lllllllllllllllllllllllllllllll}A & R & Q & Q & Q & N & I & I & V & S & S & S & I & L & D & R & S & D & V & R & V & P & Q & V & T & R & R & H & Q & E\end{array}$ ACTGTGGGAATTCTTCGTCCGCAGCTAGCAAGACAACAGCAGACAATCCGAGCCAAATGGCCAACCAATCAGCATGTGCAAACGCAACCG 1787 $\begin{array}{lllllllllllllllllllllllllllllll}\mathrm{T} & \mathrm{V} & \mathrm{G} & \mathrm{I} & \mathrm{L} & \mathrm{R} & \mathrm{P} & \mathrm{Q} & \mathrm{L} & \mathrm{A} & \mathrm{R} & \mathrm{Q} & \mathrm{Q} & \mathrm{Q} & \mathrm{T} & \mathrm{I} & \mathrm{R} & \mathrm{A} & \mathrm{K} & \mathrm{W} & \mathrm{P} & \mathrm{T} & \mathrm{N} & \mathrm{Q} & \mathrm{H} & \mathrm{V} & \mathrm{Q} & \mathrm{T} & \mathrm{Q} & \mathrm{P}\end{array}$ CAACAAACAGAGAACCCTTGGCTATCACGTCTAGAACATATACGGCAACGGCACCAGACTTCACAACTGCATACGACCAGCAATGAAACA 1877

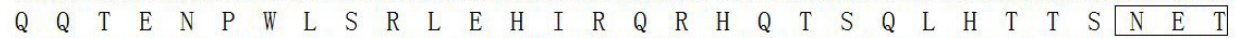
AATACAAGACAAGAAGATACTTTCCCACAGACTATAAGCTCTTTAATTTCGGATATTGCACATGTTCATGACGTTAGAATTGTGCAATTG 1967 $\begin{array}{lllllllllllllllllllllllllllllll}N & T & R & Q & E & D & T & F & P & Q & T & I & S & S & L & I & S & D & I & A & H & V & H & D & V & R & \text { I } & V & Q & L\end{array}$ AAAACCCCCAAAACTGGCACAGAACAATCAGGGCAGTCAGCAATATCTGTTCAAAACCATTTCCCGGAAAGAACTGTACAGCTGCATCAG 2057 $\begin{array}{lllllllllllllllllllllllllllllll}K & T & P & K & T & G & T & E & Q & S & G & Q & S & A & I & S & V & Q & N & H & F & P & E & R & T & V & Q & L & H & Q\end{array}$ ATACCTATCAAAGAGACTGTGTCGCCCTTGCAAATTACATTTACAACTGCGACTCCAAATTTTGCTAGAATAAATGACTCTCTGAAGAAG 2147 $\begin{array}{lllllllllllllllllllllllllllllll}\text { I } & P & I & K & E & T & V & S & P & L & Q & I & T & F & T & T & A & T & P & N & F & A & R & I & N & D & S & L & K & K\end{array}$ CAACCGCATTTTCAGCCATCAACAGAAGCAGTGATATCTGGTAAAACTGGCATCATCCGCAGCGAGAAAACGCTGAACAACCTAGACAAT 2237 $\begin{array}{lllllllllllllllllllllllllllllllllll}Q & P & H & F & Q & P & S & T & E & A & V & I & S & G & K & T & G & I & I & R & S & E & K & T & L & N & N & L & D & N\end{array}$ GGGATTCACCTTTCCAGTCAGGTAATGCAGGTCTCGAGCGAGACGTAACAGTAGCCAGAAGATTAATCCTTGAAACACAAACTCACAATA 2327 G

CAAAAGTTCCAGATCACTGGGTTACAACACAGGTTCCATCTCAAAAGCCGAGGTCCTTTACCACGGTTACCAACGCCCCCGTCTTTGGTA 2417 GTCGTCAGTCCATAACTTGGACAACGACAGAGGCTACTACGACTCTTTCCACGGAAAATCCTCTGGCAAAGCGAAGCCGTATCCAGCAAG 2507 AGCATATGAGAATGCACAACCAGACGATTGCACGTCAAAAGCAGCAGGAAGAAATAATACGAAAAGAACAACTTGAAATGCTCCGGAGAC 2597 AACAAGAGGAATTGCACAGAACTATGGAGCTACAGCAAAAAAAAAAAACCTATAGTG

Figure 3. The nucleotide and deduced amino acid sequence of the Cda in Hyriopsis cumingii (GenBank accession No. JN582040). Above the sequence, the signal peptide, catalytic domain (Polysacc_deac_1 domain), predicted $\mathrm{N}$-glycosylation sites are underlined, grayed, and boxed, respectively. 


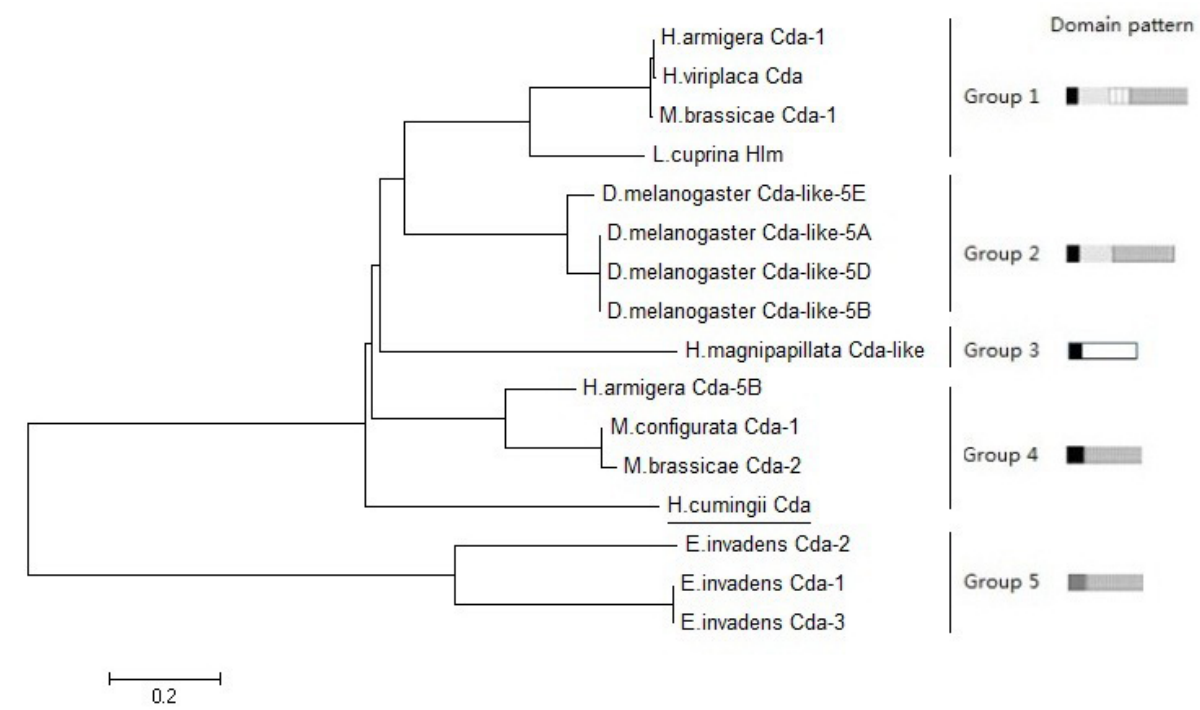

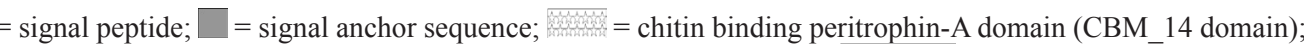
$=$ low-density lipoprotein receptor class A domain (LDLa domain); $\square=$ catalytic NodB homology domain of the carbohydrate esterase 4 superfamily (CE4_SF); like proteins (CE4_CDA_like_1)

Figure 4. Phylogenetic tree of chitin deacetylase $(C d a)$ sequences in invertebrates. The domain patterns were used for constructing the phylogenetic tree. Amino acid sequences of full-length Cda were analyzed using the neighborjoining method in the Mega 5.0 program. The protein sequences used for phylogenetic analysis were as follows: Helicoverpa armigera (Cda-1: ADB43610.1; Cda-5B: ADB43612.1), Heliothis viriplaca (Cda: ACZ71481.1), Mamestra brassicae (Cda-1: AEI30868.1; Cda-2: AEI30869.1), Lucilia cuprina (HLM: ABI95429.1), Drosophila melanogaster (Cda-like-5A: NP_722589.1; Cda-like-5B: NP_722590.2; Cda-like-5D: NP_001097044.1; Cdalike-5E: NP_001097045.1), Hydra magnipapillata (Cda-like: XP_002154465.1), Mamestra configurata (Cda-1: ACD37362.1), and Entamoeba invadens (Cda-1: ABB90108.1; Cda-2: ABB90109.1; Cda-3: ABB90110.1).

\section{Constitutive expression of $\mathrm{Chi}-3$ and $\mathrm{Cda}$ genes in various tissues}

To gain insight into the possible physiological functions of the 2 putative chitin metabolic enzymes under study, a determination of their tissue distribution was performed with RT-PCR. As shown in Figure 5, Cda was expressed in the blood and in a wide range of tissues, including mantle, liver, stomach, kidney, intestine, gill, and foot, whereas Chi-3 was expressed in all of those tissues but not in the blood. Hemocytes are considered the main immune cells in mollusks (Cheng, 1996) and have been shown to express a humoral factor (Montagnani et al., 2001) and a potential cytokine homologue (Lelong et al., 2007) in response to bacterial infection. Chitinase is probably involved in defense against and degradation of chitin-containing pathogens such as fungi, nematodes, and protozoa (Badariotti et al., 2007). The absence of expression of $\mathrm{HcChi-3}$ messenger RNA in blood is reminiscent of the results obtained for $C$. gigas $C h i-3$, which is also expressed at very low quantities in the blood (Badariotti et al., 2011). These results indicate that other Chi may be involved in the $H$. cumingii immune system; however, no tissue-specific differences were found in the expression of $\mathrm{HcCla}$ gene transcripts. 


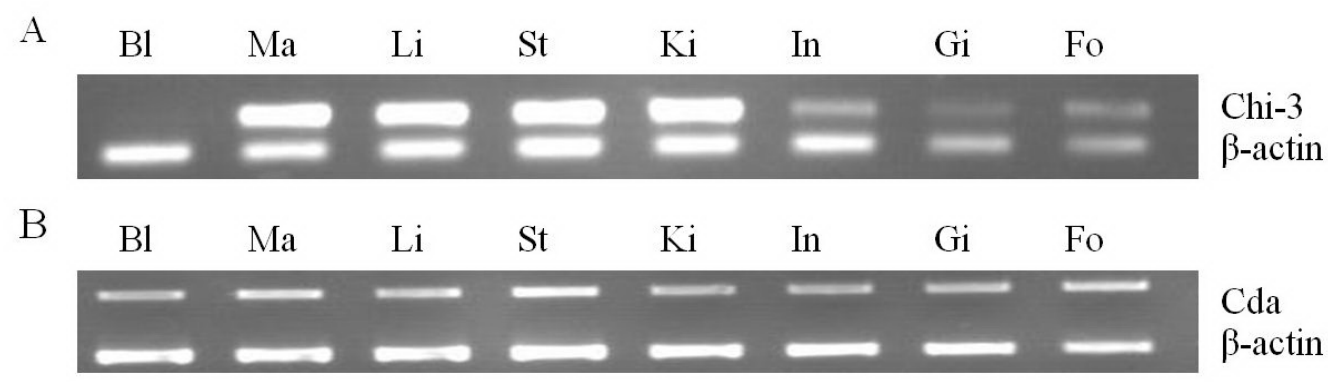

Figure 5. Tissue distribution of (A) Chi-3 and (B) Cda mRNA in Hyriopsis cumingii by RT-PCR analysis using $\beta$-actin as the internal reference. $\mathrm{Bl}=$ blood; $\mathrm{Ma}=$ mantle; $\mathrm{Li}=$ liver; $\mathrm{St}=$ stomach; $\mathrm{Ki}=$ kidney; $\mathrm{In}=$ intestines; $\mathrm{Gi}=$ gill; $\mathrm{Fo}=$ foot.

Data about $C d a$ in mollusk at present are relatively rare. According to Minagawa et al. (2007), chitin and chitosan have properties that accelerate wound healing. In addition, Riccardo (2009) has concluded that the chitins and chitosans together with some of their derivatives obtained through chemical or enzymatic means are protagonists in the scenario of wound healing and bone regeneration. Hence, does $\mathrm{HcCla}$ play a role in the various tissues by regulating chitosan, or do $\mathrm{HcChi}$ and $\mathrm{HcCda}$ play possible roles in mollusk shell regeneration by regulating chitin and chitosan?

\section{Induced expression of $\boldsymbol{C h i - 3}$ and $\boldsymbol{C d a}$ after shell damage}

Induced expression of $C h i-3$ and $C d a$ was investigated after shell damage. Chi-3 transcript levels were upregulated significantly $(\mathrm{P}<0.05) 12 \mathrm{~h}$ after shell damage, and expression reduced gradually thereafter; however, transcript levels of $C d a$ did not change significantly $(\mathrm{P}>0.05)$ (see Figure 6). Chitin/chitosan, silk fibroin protein, and acidic macromolecules are important components of shell formation (Furuhashi et al., 2009). According to the molecular mechanism proposed by Suzuki et al. (2009) for nacreous layer formation in P. fucata, chitin plays an important role as a "bridge" for protein collection during nacreous layer formation. However, the interactions between chitin/chitosan and protein have not been clearly resolved. To date, most in vitro experiments with chitin protein compounds indicate intercalation of the silk into the chitins. However, the X-ray diffraction and infrared spectroscopy experiments of Falini et al. (2003) suggest that a defined interface exists between chitin and the gels of silklike proteins in vivo, and that these interactions occur mainly via the chitin acetyl groups. In that scenario, chitin deacetylation into chitosan is unhelpful for interactions between chitin and protein, which has been suggested to occur via covalent modification of chitin with silk derivatives (Weiss et al., 2009). In both adult and larval developmental stages, modified chitin is thought to play a fundamental role in the biomineralization of mollusk shells (Weiss et al., 2009). In the present study, the distinct induced expression differences between $\mathrm{HcChi}-3$ and $\mathrm{HcCda}$ suggest that $\mathrm{HcChi-3}$ might hydrolyze superfluous chitin during shell recovery and play a role in shell formation in mollusks. However, $\mathrm{HcCla}$ expression did not change significantly $(\mathrm{P}>0.05)$ in response to shell damage, but this response may maintain a certain degree of acetylation in chitin/chitosan. 
A

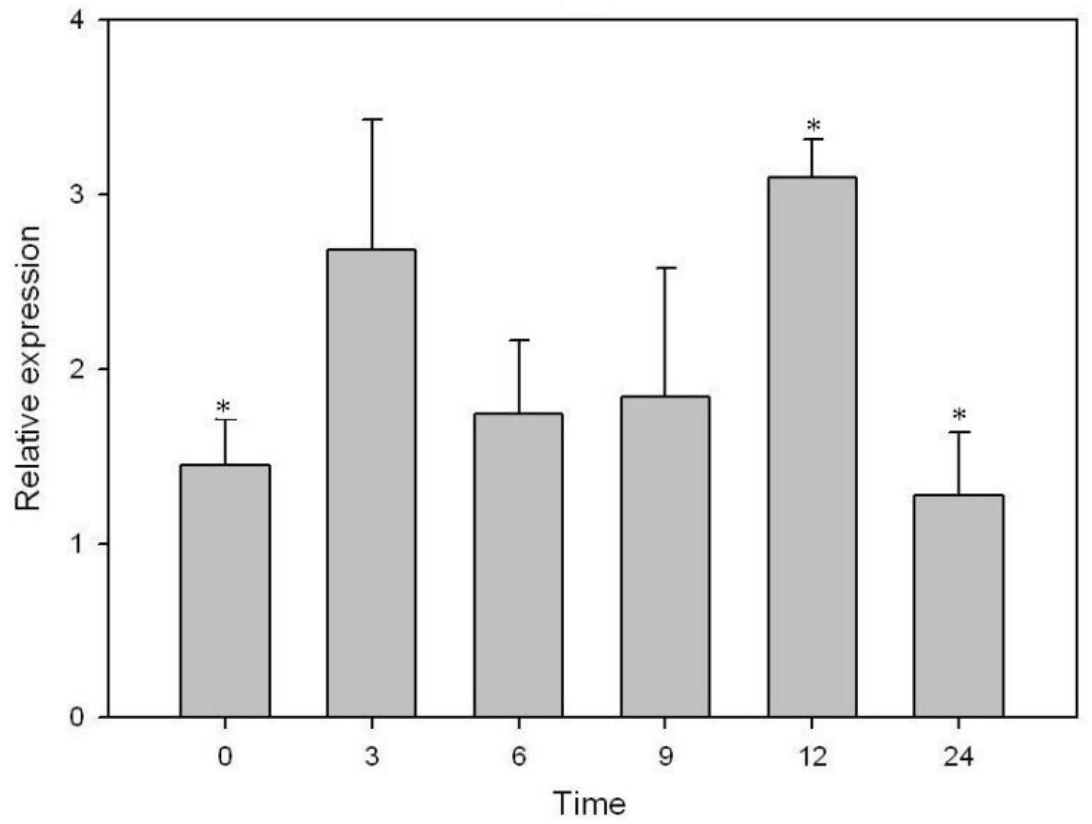

B

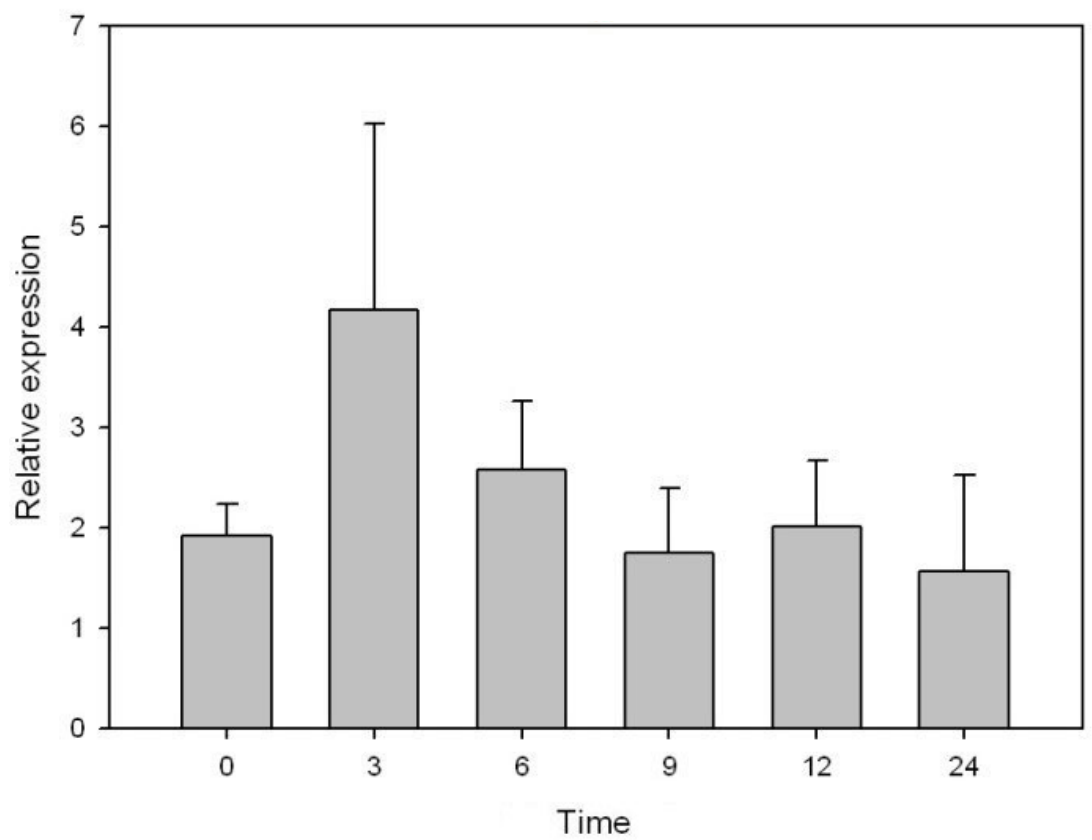

Figure 6. Quantification by qRT-PCR of (A) $C h i-3$ and (B) $C d a$ mRNA in the mantle after shell damage. The x-axis represents time of treatment. " 0 h" indicates non-treatment samples. The quantities of Chi-3 and Cda transcripts were normalized to $\beta$-actin mRNA. *Significant difference $(\mathrm{P}<0.05)$. 
We cloned and characterized 2 metabolic enzyme genes, $\mathrm{HcChi}-3$ and $\mathrm{HcCda}$. HcChi-3 had the typical structural motifs of chitinases, including a signal peptide, a glycoside hydrolase family 18 domain, and 2 CBM14 domains. $H c C d a$ had a signal peptide and a Polysacc_deac_1 domain but showed no chitin-binding domain and was phylogenetically clustered in group 4 (see Figure 5). The lack of $\mathrm{HcChi-3}$ expression in blood indicated that other Chi may be involved in the $H$. cumingii immune system. This study highlights the presence of covalently attached, hydrophobic amino acid side chains in the chitin matrix that interact mainly via the acetyl groups of the chitin.

\section{ACKNOWLEDGMENTS}

Research supported by the Key Basic Project from Science and Technology Commission of Shanghai Municipal Government (\#10JC1406300) and the National Natural Science Foundation of China (\#31101939).

\section{REFERENCES}

Badariotti F, Thuau R, Lelong C, Dubos MP, et al. (2007). Characterization of an atypical family 18 chitinase from the oyster Crassostrea gigas: evidence for a role in early development and immunity. Dev. Comp. Immunol. 31: 559-570.

Badariotti F, Lelong C, Dubos MP and Favrel P (2011). Identification of three singular glycosyl hydrolase family 18 members from the oyster Crassostrea gigas: Structural characterization, phylogenetic analysis and gene expression. Comp. Biochem. Physiol. B Biochem. Mol. Biol. 158: 56-63.

Bai ZY, Yin YX, Hu SN, Wang GL, et al. (2010). Identification of genes potentially involved in pearl formation by expressed sequence tag analysis of mantle from freshwater pearl mussel (Hyriopsis cumingii lea). J. Shellfish Res. 29: 527-534.

Bendtsen JD, Nielsen H, von HG and Brunak S (2004). Improved prediction of signal peptides: SignalP 3.0. J. Mol. Biol. 340: 783-795.

Cheng TC (1996). Hemocytes: Forms and Functions. In: The Eastern Oyster Crassostrea virginica (Kennedy VS, Newell RIE and Eble AF, eds.). Maryland Sea Grant Book, College Park, Maryland, 299-333.

Dixit R, Arakane Y, Specht CA, Richard C, et al. (2008). Domain organization and phylogenetic analysis of proteins from the chitin deacetylase gene family of Tribolium castaneum and three other species of insects. Insect Biochem. Mol. Biol. 38: 440-451.

Falini G, Weiner S and Addadi L (2003). Chitin-silk fibroin interactions: relevance to calcium carbonate formation in invertebrates. Calcif. Tissue Int. 72: 548-554.

Furuhashi T, Schwarzinger C, Miksik I, Smrz M, et al. (2009). Molluscan shell evolution with review of shell calcification hypothesis. Comp. Biochem. Physiol. B Biochem. Mol. Biol. 154: 351-371.

Huang QS, Yan JH, Tang JY, Tao YM, et al. (2010). Cloning and tissue expressions of seven chitinase family genes in Litopenaeus vannamei. Fish Shellfish Immunol. 29: 75-81.

Jeanmougin F, Thompson JD, Gouy M, Higgins DG, et al. (1998). Multiple sequence alignment with Clustal X. Trends Biochem. Sci. 23: 403-405.

Kumirska J, Czerwicka M, Kaczynski Z, Bychowska A, et al. (2010). Application of spectroscopic methods for structural analysis of chitin and chitosan. Mar. Drugs 8: 1567-1636.

Lelong C, Badariotti F, Le Quéré H, Rodet F, et al. (2007). Cg-TGF-beta, a TGF-beta/activin homologue in the Pacific Oyster Crassostrea gigas, is involved in immunity against Gram-negative microbial infection. Dev. Comp. Immunol. 31: 30-38.

Li JL, Qian RH, Bao BL, Wang GL, et al. (2005). RAPD analysis on genetic diversity among the stocks of Hyriopsis cumingii from the five large lakes of China. J. Shanghai Fish. Univ. 14: 1-5.

Liu YY (1979). Economic Fauna of China (Freshwater mollusk). Science Press, Beijing, 83-84.

Livak KJ and Schmittgen TD (2001). Analysis of relative gene expression data using real-time quantitative PCR and the $2^{-\Delta \Delta C T}$ Method. Methods 25: 402-408.

Minagawa T, Okamura Y, Shigemasa Y, Minami S, et al. (2007). Effects of molecular weight and deacetylation degree of chitin/chitosan on wound healing. Carbohydr. Polym. 67: 640-644.

Genetics and Molecular Research 11 (4): 4539-4551 (2012) 
Montagnani C, Le Roux F, Berthe F and Escoubas JM (2001). Cg-TIMP, an inducible tissue inhibitor of metalloproteinase from the Pacific oyster Crassostrea gigas with a potential role in wound healing and defense mechanisms(1). FEBS Lett. 500: 64-70.

Mount AS, Wheeler AP, Paradkar RP and Snider D (2004). Hemocyte-mediated shell mineralization in the eastern oyster. Science 304: 297-300.

Proespraiwong P, Tassanakajon A and Rimphanitchayakit V (2010). Chitinases from the black tiger shrimp Penaeus monodon: phylogenetics, expression and activities. Comp. Biochem. Physiol. B Biochem. Mol. Biol. 156: 86-96.

Ravi Kumar MNV (2000). A review of chitin and chitosan applications. React. Funct. Polym. 46: 1-27.

Riccardo AAM (2009). Chitosan composites with inorganics, morphogenetic proteins and stem cells, for bone regeneration. Carbohydr. Polym. 83: 1433-1445.

Suzuki M, Saruwatari K, Kagure T, Yamamoto Y, et al. (2009). An acidic matrix protein, Pif, is a key macromolecule for nacre formation. Science 325: 1388-1390.

Wang GL, Wang JJ and Li JL (2006). Preliminary study on applicability of microsatellite primers developed from Crassostrea gigas to genomic analysis of Hyriopsis cumingii. J. Fish. China 1: 30-38.

Weiss IM, Kaufmann S, Heiland B and Tanaka M (2009). Covalent modification of chitin with silk-derivatives acts as an amphiphilic self-organizing template in nacre biomineralisation. J. Struct. Biol. 167: 68-75.

Zhang J, Zhang X, Arakane Y, Muthukrishnan S, et al. (2011). Identification and characterization of a novel chitinaselike gene cluster (AgCht5) possibly derived from tandem duplications in the African malaria mosquito, Anopheles gambiae. Insect Biochem. Mol. Biol. 41: 521-528.

Zhou J, Gao YF, Li L, Zhai HN, et al. (2011). Identification and functional characterization of a putative 17ß-hydroxysteroid dehydrogenase 12 in abalone (Haliotis diversicolor supertexta). Mol. Cell. Biochem. 354: 123-133.

Zhu Q, Arakane Y, Banerjee D, Beeman RW, et al. (2008). Domain organization and phylogenetic analysis of the chitinase-like family of proteins in three species of insects. Insect Biochem. Mol. Biol. 38: 452-466. 